\title{
Determination the maximum load capacity of the welded structure of the transport carriage in operation
}

\author{
Vladislav Baniari ${ }^{1, *}$, Marián Handrik ${ }^{1}$, Milan Vaško ${ }^{1}$, Ján Kortiš $^{2}$, Luboš Daniel $^{2}$ \\ ${ }^{1}$ University of Žilina, Faculty of Mechanical Engineering, Department of Applied Mechanics, \\ Univerzitná 8215/1, Žilina, Slovakia \\ ${ }^{2}$ University of Žilina, Faculty of Civil Engineering, Department of Structural Mechanics, Univerzitná \\ $8215 / 1$, Žilina, Slovakia
}

\begin{abstract}
The article presents a calculation procedure for determining the maximum permissible load on the welded structure of the transport carriage. During the transport carriages operation inside the production hall there was no breakage of the welding joints. The use of carriages outside the hall and with an uneven surface began to create cracks and fractures in the weld joints. The values of vertical accelerations that were generated by running on uneven surfaces were determined by experimental measurement. To avoid cracks in welded joints, the maximum permissible load value of the transport carriage was subsequently determined by calculation using FEM.
\end{abstract}

Keywords: weld, weld joint, crack, deformation, FEM, FE analysis

\section{Introduction}

The purpose of the carriage is transport some various kinds of costs. During use of the carriage in the exterior on the construction were started some deformations which are looked like a rift of welding joints. The carriage is pulling by the same standard electric tractor in the interior and in the exterior as well.

Based on the request there were made some experimental measurements by using the carriage in the exterior $[1,2]$. Subsequently, their results were evaluated and they were used as an input data for the calculation by the Finite Element Method (FEM) [3].

\section{Experimental measurement and evaluation of results}

During the process of measurement there were used piezoelectric accelerometers which were fitted on unsuspended axle near the wheels (Fig. 1) [4, 5]. Accelerometers were marked ACC 1 till ACC 4 according Fig. 2.

\footnotetext{
* Corresponding author: vladislav.baniari@,fstroj.uniza.sk

Reviewers: Marcin Kubiak, Bohuš Leitner
} 

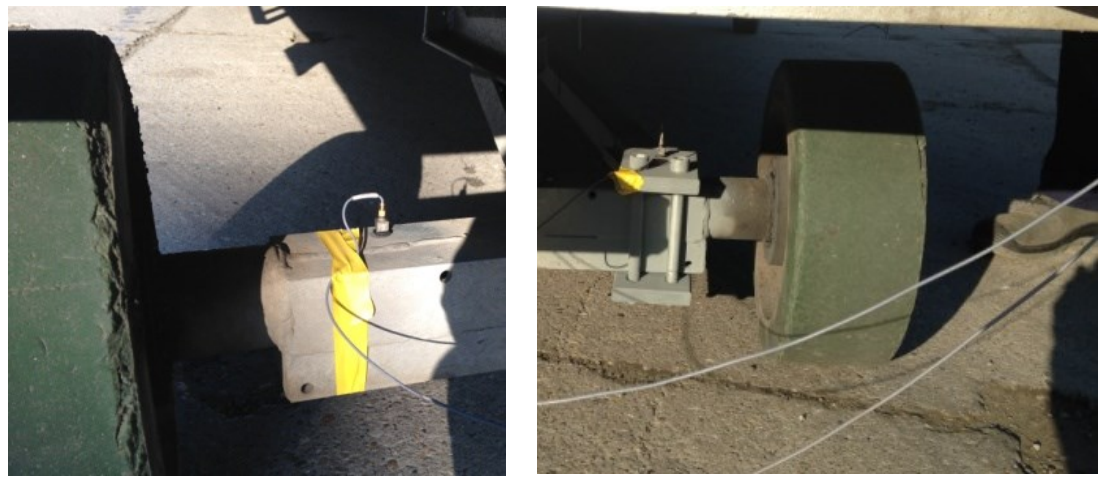

Fig. 1. Accelerometers on axles

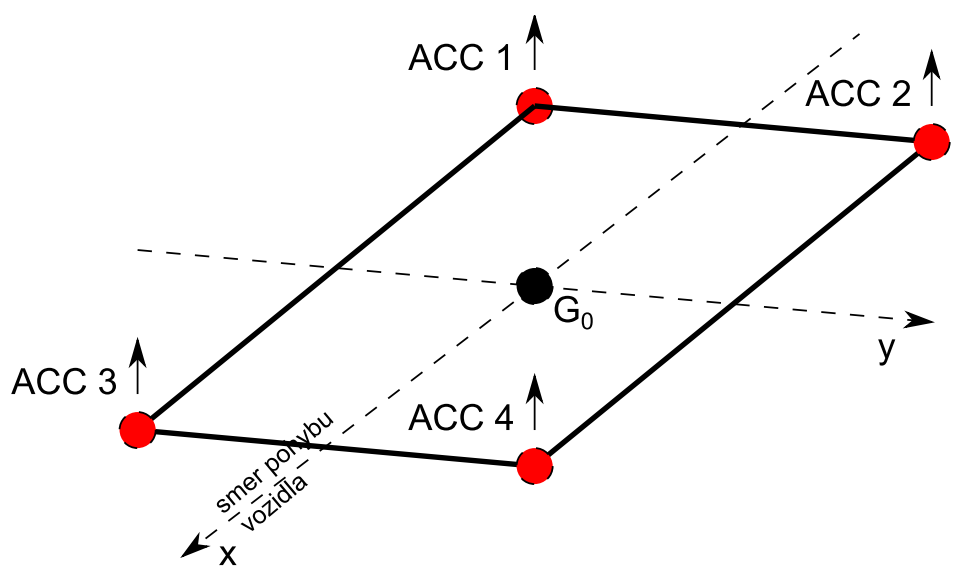

Fig. 2. Marking of accelerometer versus move direction

Steel frames were used as the burden. They were typed as the hardest possible way of the burden which can be transported by this carriage. Four types of measurements there were noted down by using the accelerometers $[6,7]$.

Several values with different tops were measured by the process of measurement. The highest tops were chosen and written into the Table 1.

Table 1. Measured accelerations

\begin{tabular}{|c|c|c|c|c|c|c|c|c|}
\hline \multirow{2}{*}{ Motion } & \multicolumn{2}{|c|}{$\begin{array}{c}\text { max ACC1 } \\
{\left[\mathbf{m s}^{-2}\right]}\end{array}$} & \multicolumn{2}{c|}{$\begin{array}{c}\text { max ACC2 } \\
{\left[\mathbf{m s}^{-2}\right]}\end{array}$} & \multicolumn{2}{c|}{$\begin{array}{c}\text { max ACC3 } \\
{\left[\mathbf{m s}^{-2}\right]}\end{array}$} & \multicolumn{2}{c|}{$\begin{array}{c}\text { max ACC4 } \\
{\left[\mathbf{m s}^{-2}\right]}\end{array}$} \\
\cline { 2 - 9 } & plus & minus & plus & minus & plus & minus & plus & minus \\
\hline $\begin{array}{c}\text { Slow motion on a paneled } \\
\text { road (empty carriage) }\end{array}$ & 5.114 & -5.113 & 4.797 & -5.12 & 5.116 & -5.114 & 5.112 & -5.117 \\
\hline $\begin{array}{c}\text { Fast motion on a paneled } \\
\text { road (empty carriage) }\end{array}$ & 14.405 & -8.046 & 14.699 & -9.09 & 10.859 & -10.14 & 11.428 & -7.863 \\
\hline $\begin{array}{c}\text { Slow motion on a railway } \\
\text { crossing (empty carriage) }\end{array}$ & 13.296 & -7.82 & 10.314 & -9.69 & 14.735 & -10.5 & 11.085 & -7.86 \\
\hline $\begin{array}{c}\text { Slow motion on a railway } \\
\text { crossing (loaded carriage) }\end{array}$ & 12.927 & -8.07 & 12.113 & -8.64 & 12.674 & -8.94 & 10.684 & -8.21 \\
\hline
\end{tabular}




\section{FEM analyses}

The basic request for the stress analysis of the transport carriage is to analyze the condition of the state of stress in the carriage parts of the construction by the transition of the carriage through the obstacle. We can see from the results of some experimental measurements that when the empty carriage went through the obstacle by the speed of $4-6 \mathrm{~km} \cdot \mathrm{h}^{-1}$ appeals on the construction additional acceleration in vertical way in the size $a_{p}=14.735 \mathrm{~m} \cdot \mathrm{s}^{-2}$. This value is the highest of the measured values and it represents the biggest load which effects the construction of the carriage in the exterior $[5,8,9]$.

On the model of the carriage parts was applied additional acceleration in the value of $a_{p}=14.735 \mathrm{~m} \cdot \mathrm{s}^{-2}$. The complete acceleration was created by the gravitation and the additional acceleration of $a_{y}=24.545 \mathrm{~m} \cdot \mathrm{s}^{-2}$.

The weight of superstructure included the door was substituted by the force effect in the places of connections of the superstructure into the carriage part of the construction of the transport carriage. The weight of the superstructure was determined as the conjunction of the result acceleration and the weight of the construction of the superstructure. The weight of the load represents the pressure on the floor which can be given as the weight on one square meter multiplied by the value of the result acceleration $[1,10,11]$.

The construction will be suspended with the aim of the permission of deformations of the construction in the places of the wheels. The elastic constrain of the construction is chosen from the reason of small spring loading of the wheels and friction constrain of the wheel with the roadway.

The construction of the carriage is created by the rolled profiles. The thickness of the rolled profiles is much smaller than other dimensions of the profiles in these construction elements. This type of the construction in the working out of deformation-stress analysis can be substituted by shell elements $[4,12]$.

The linear elastic material model was used during the preparation of the mathematical model. The usage of the linear material model is adequate and it is not needed to use nonlinear material models, whereas there is the basic expectation that the construction has to be operated from the point of view of the secure use in the allowed stresses area. This ensures that the stress is lower than the Yield strength $[1,13]$.

\subsection{Mesh of the geometric model}

The geometrical model was created in CAD system and imported into the CAE software with divided parts. According to standard progress there were extracted middle planes parts which will be working out through the shell elements.

The remaining parts are made by the solid elements as we can see in the Fig. 3 and 4. 

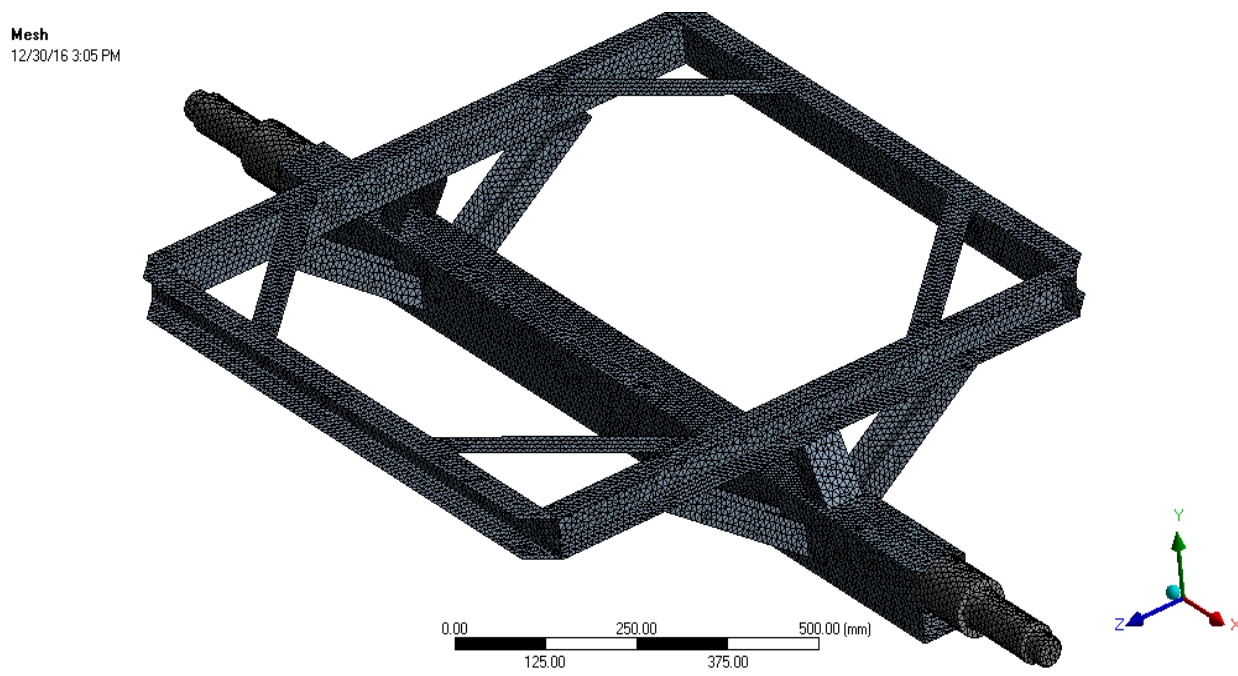

Fig. 3. Undercarriage with solid elements

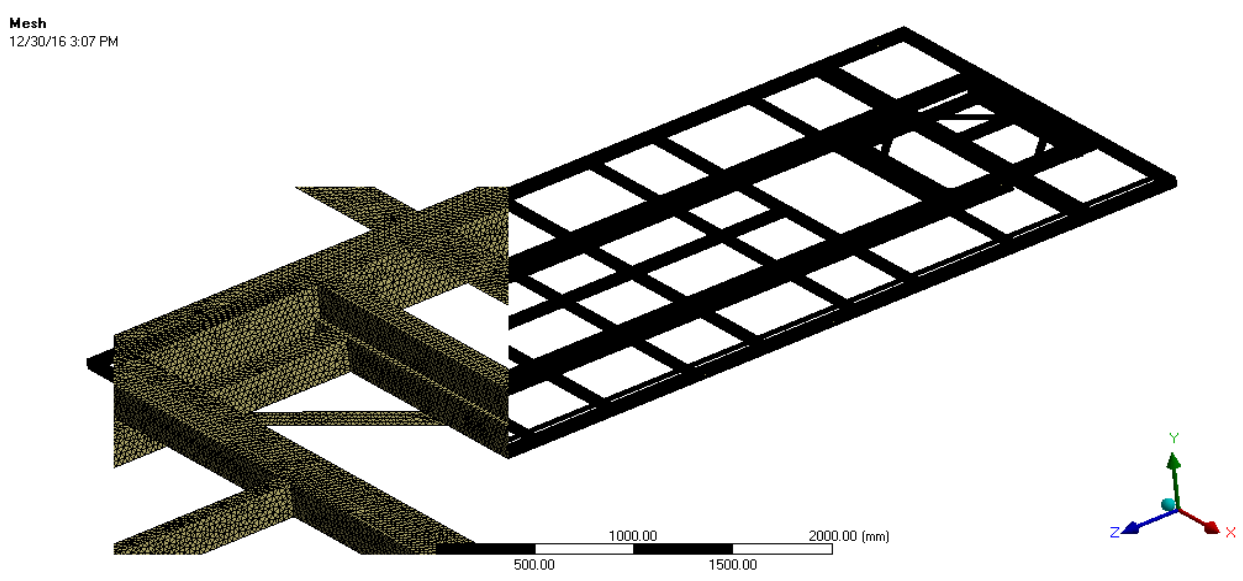

Fig. 4. Frame with shell elements

\subsection{Boundary conditions}

Springs were used in terms of deformation boundary conditions. Generally, there were used 12 springs on the model according to the Fig. 5. The forces boundary conditions were depended on the parts of the construction and their joints. The weight of the construction and substruction were applied as a force. The weight of load was applied by the way of pressure on the floor $[14,15]$.

The created finite element model of the transport carriage is made from 10 independent bodies and 10 independent meshes of the finite elements as well $[16,17]$. The meshes are connected through the contact which is defined between following parts of the construction:

- the contact between the wheel pins and the undercarriage with the gluemesh in 4 places,

- the contact between the undercarriage and the turning platform with the gluemesh in 2 places, 
- the contact between the frame and the turning platform with the gluemesh in the 2 places,

- the contact between the floor and the frame without friction in 1 place. The contact between the floor and the frame has to be carried by normal load; tangential components making the membrane load in the floor cannot be carried. The floor is laid on the frame - it is not connected hard.

Ram

12/30/16 3:16 PM
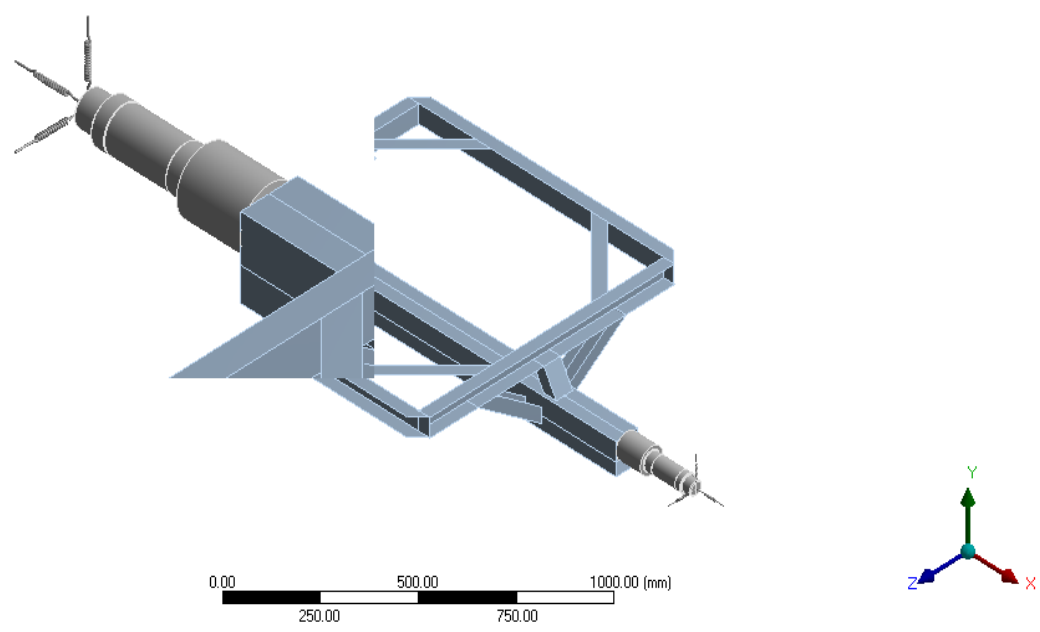

Fig. 5. Deformation boundary condition on the wheel shaft

\section{FEA results}

According to Figures 6 to 9 we can see two conditions which were solved by von Mises. The first condition is marked as Time 1 and its load is in the static way, i.e. without accelerations. The second condition is marked as Time 19 and it is dynamic, i.e. with accelerations.

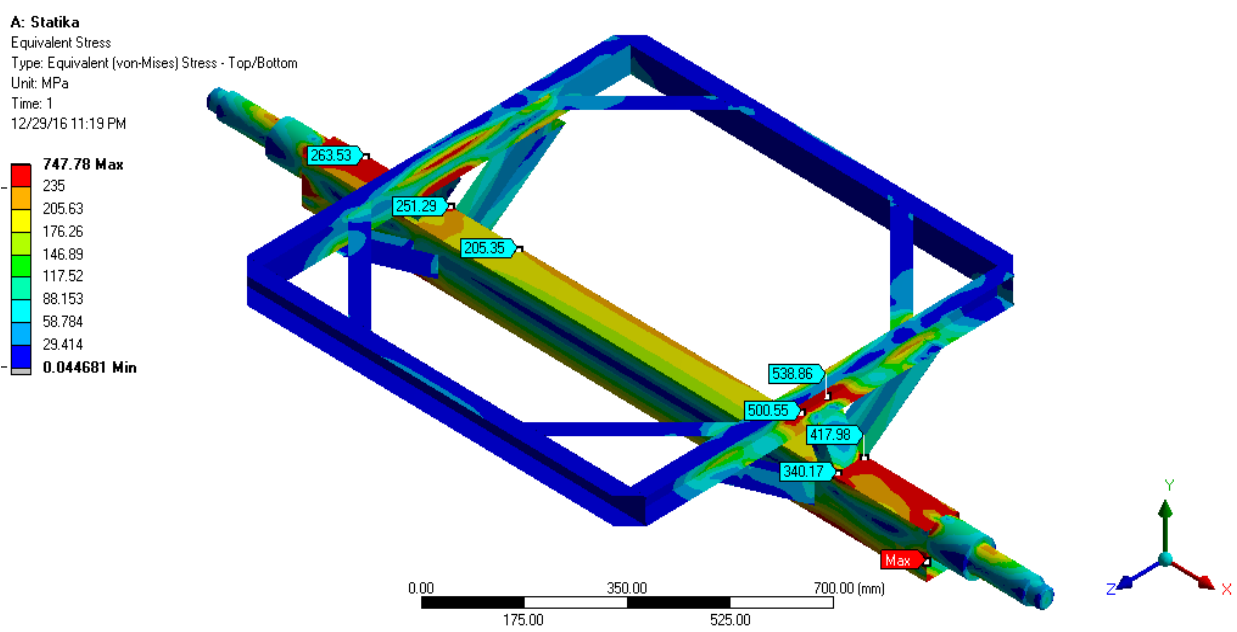

Fig. 6. Von Mises stress on undercarriage in Time 1 


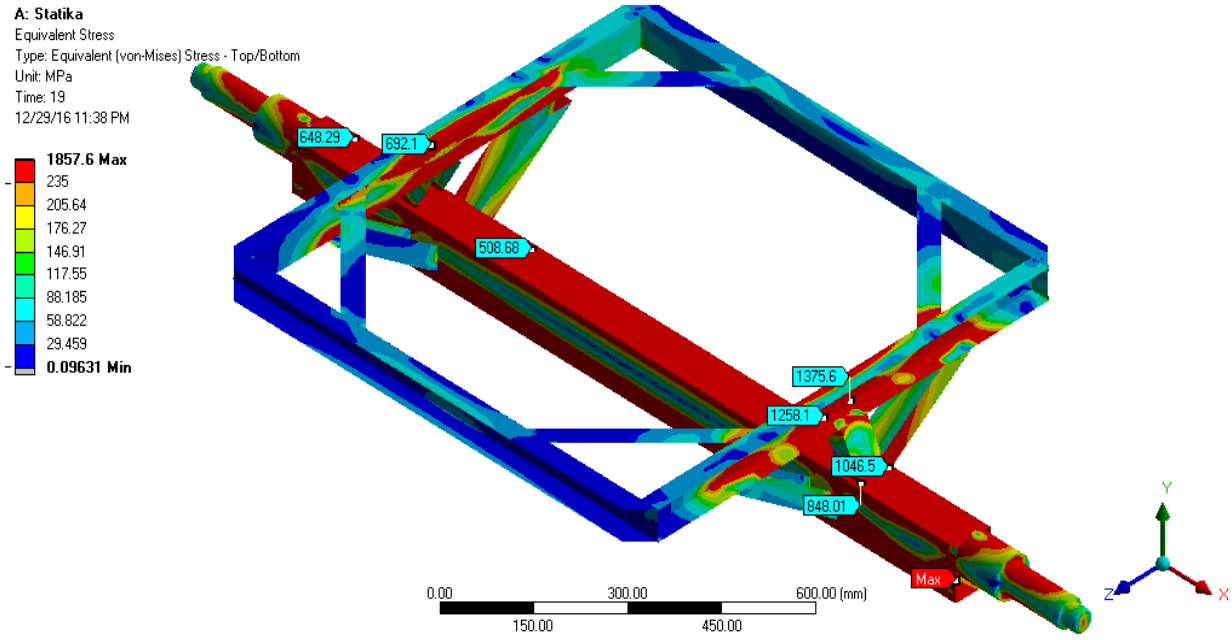

Fig. 7. Von Mises stress on undercarriage in Time 19

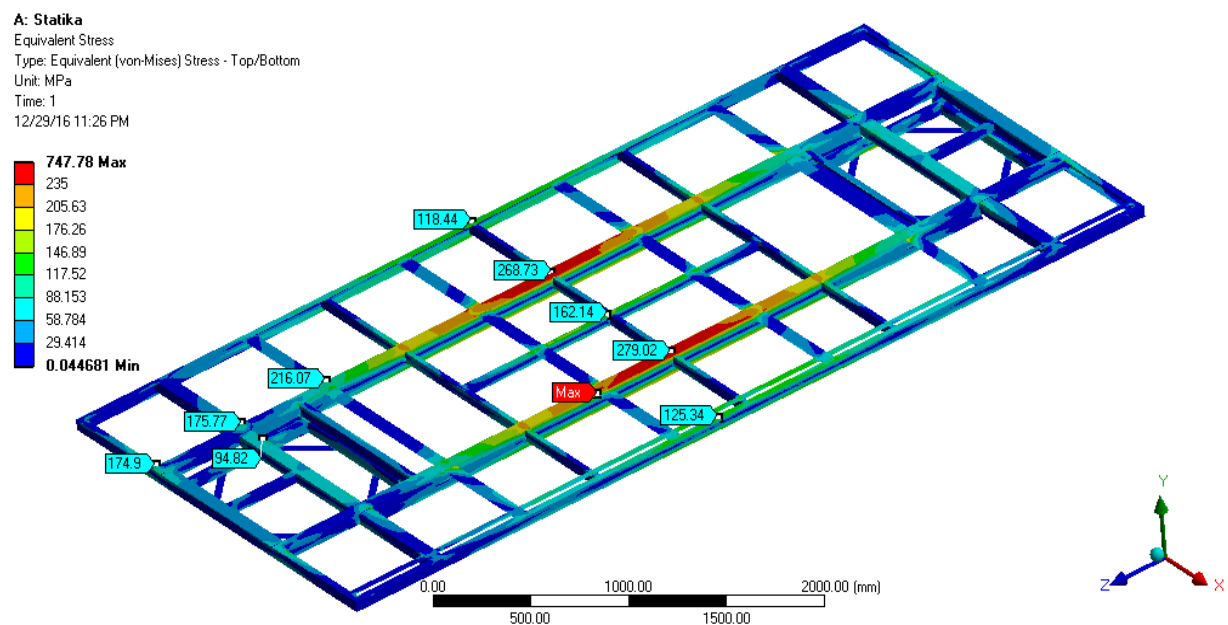

Fig. 8. Von Mises stress on a frame in Time 1 


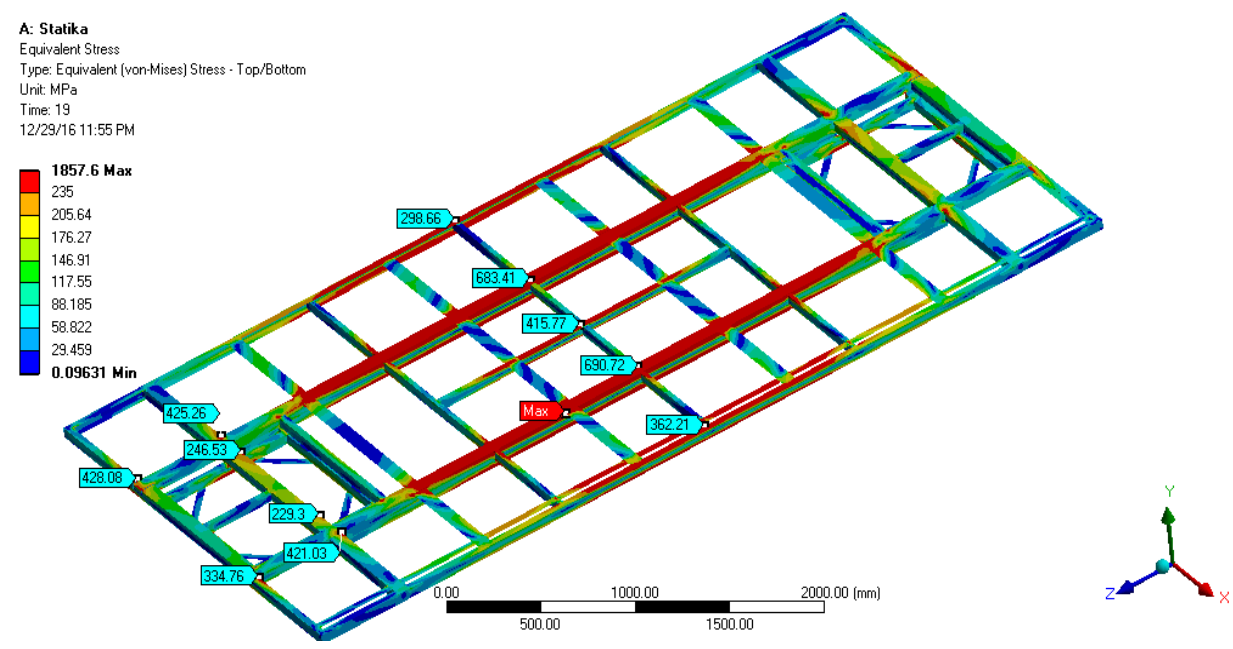

Fig. 9. Von Mises stress on a frame in Time 19

Solution for both problem versions clearly show that the construction cannot hold in the exterior and the caused stress in tolerable transcending the allowing Yield stress of the S 235 material. Welded joints are loaded excessively and dynamic effects may cause cracking of the joints and subsequent destruction of the frame.

\section{Conclusion}

The transport carriage has been designed to operate in the interior of the production hall. Usage the transport carriage during transport of the material in outdoor environments with significantly uneven surface causes additional loads from dynamic effects.

Local points where the stress state exceeds the yield strength were determined by analyzing the stress state of the welded structure of the carriage under static load mode. The stress state analysis was done also for dynamic load mode. Results of the analysis have shown that there is significantly exceeded yield strength and maximum allowable load of the carriage needs to be reduced to approximately $1 / 3$ of the load.

The proposed reductions in the carrying capacity of the transport carriage allow safe operation and significantly reduce the probability of fatigue cracks at the weld joints. However, the carriage failure due to fatigue cracks cannot be completely ruled out due to the unknown history of the previous operation. Existing cracks that arose in the previous operation may continue to grow even at reduced load.

\section{References}

1. M. Handrik, P. Kopas, V. Baniari, M. Vaško, M. Sága, Analysis of stress and strain of fatigue specimens localised in the cross-sectional area of the gauge section testing on bi-axial fatigue machine loaded in the high-cycle fatigue region. Procedia Engineering 177, 516-519 (2017)

2. R. Halama, P. Macura, L. Pečenka, F. Fojtík, M. Šofer, Experimental Analysis of Residual Stresses in Backup Roll and FE Solution. Experimental Stress Analysis - $49^{\text {th }}$ Int. Scient. Conf. on Experimental Stress Analysis, 85-90 (2011)

3. K. J. Bathe, Finite Element Procedures. (Prentice Hall, New Jersey, 1982) 
4. L. Jakubovičová, M. Sága, Computational analysis of contact stress distribution in the case of mutual stewing of roller bearing rings. Novel Trends in Production Devices and Systems, Applied Mechanics and Materials 474, 363-368 (2014)

5. J. Gerlici, T. Lack, Modified HHT method for vehicle vibration analysis in time domain utilisation. Applied Mechanics and Materials 486, 396-405 (2014)

6. J. Ondrouch, P. Ferfecki, Z. Poruba, Active vibration reduction of rigid rotor by kinematic excitation of bushes of journal bearings. Metalurgija 49 (2), 107-110 (2010)

7. R. Grega, J. Homišin, J. Krajňák, M. Urbanský, Analysis of the impact of flexible couplings on gearbox vibrations. Scientific Journal of Silesian University of Technology-Series Transport 91, 43-50 (2016)

8. A. Sapietová, V. Dekýš, Dynamic analysis of rotating machines in MSC.ADAMS. Procedia Engineering 136, 143-149 (2016)

9. R. Grega, J. Krajňák, L. Žul'ová, G. Fedorko, V. Molnár, Failure analysis of driveshaft of truck body caused by vibrations. Engineering Failure Analysis 79, 208-215 (2017)

10. J. Vavro, J. Vavro Jr., P. Kováčiková, R. Bezdedová, The optimization of the materials properties for the passenger cars in dependence on defect distribution at the dynamic loading. Procedia Engineering 136, 114-119 (2016)

11. A. Vaško, J. Belan, L. Kuchariková, E. Tillová, Low and high frequency fatigue tests of nodular cast irons. Metalurgija 56 (1-2), 25-28 (2017)

12. J. Rojek, M. Hyrcza-Michalska, A. Bokota, W. Piekarska, Determination of mechanical properties of the weld zone in tailor-welded blanks. Archives of Civil and Mechanical Engineering 12 (2), 156-162 (2012)

13. P. Kopas, M. Blatnický, M. Sága, M. Vaško, Identification of mechanical properties of weld joints of AlMgSi07.F25 aluminium alloy. Metalurgija 56 (1-2), 99-102 (2017)

14. V. Bulej, J. Uricek, V. Poppeova, R. Zahoransky, M. Rupikova, Study of the Workspace of Hybrid Mechanism Trivariant. Appl. Mech. and Mat., Mech. Eng. and Manufacturing 436, 366-373 (2013)

15. M. Bruna, D. Bolibruchova, R. Pastircak, Numerical simulation of porosity for Al based alloys. Procedia Engineering 177, 488-495 (2017)

16. M. Sága, P. Kopas, M. Uhríčik, Modeling and experimental analysis of the aluminium alloy fatigue damage in the case of bending-torsion loading. Procedia Engineering 48, 599-606 (2012)

17. B. Strnadel, P. Ferfecki, P. Židlík, Statistical characteristics of fracture surfaces in $X 70$ steel DWTT samples. Engineering Fracture Mechanics 112, 1-13 (2013) 